\title{
Cholera prevention and control in Asian countries
}

\author{
Mesbah Uddin Ahmed', Mario Baquilod ${ }^{2}$, Claudio Deola ${ }^{3}$, Nguyen Dong Tu', Dang Duc Anh ${ }^{4}$, Cindy Grasso ${ }^{5}$, \\ Anu Gautam ${ }^{6}$, Wan Mansor Hamzah, Seng Heng ${ }^{8}$, Sopon lamsirithaworn', Musal Kadim ${ }^{10}$, S. K. Kar ${ }^{11}$, \\ Mai Le Thi Quynh ${ }^{4}$, Anna Lena Lopez ${ }^{12}$, Julia Lynch ${ }^{13}$, Iqbal Memon ${ }^{14}$, Martin Mengel ${ }^{15}$, Vu Ngoc Long ${ }^{16}$, \\ Basu Dev Pandey ${ }^{17}$, Firdausi Quadri ${ }^{18}$, Mitra Saadatian-Elahi ${ }^{19}$, Sanjukta Sen Gupta ${ }^{20}$, Ashraf Sultan ${ }^{21}$, Dipika Sur ${ }^{22}$, \\ Dang Quang Tan ${ }^{16}$, Hoang Thi Thu Ha ${ }^{4}$, Nguyen Tran Hein ${ }^{4}$, Phan Trong Lan ${ }^{23}$, Shyam Raj Upreti ${ }^{24}$, \\ Hubert Endtz ${ }^{5 \dagger}$, N. K. Ganguly ${ }^{20 \dagger}$, Dominique Legros ${ }^{25 \dagger}$, Valentina Picot ${ }^{5+}$ and G. Balakrish Nair ${ }^{26 \dagger}$ \\ From Cholera prevention and control in Asian countries: the Initiative against Diarrheal and Enteric diseases in Asia and Africa- \\ IDEA, Vietnam \\ Hanoi, Vietnam. 06-09 March 2017
}

\begin{abstract}
Cholera remains a major public health problem in many countries. Poor sanitation and inappropriate clean water supply, insufficient health literacy and community mobilization, absence of national plans and cross-border collaborations are major factors impeding optimal control of cholera in endemic countries.

In March 2017, a group of experts from 10 Asian cholera-prone countries that belong to the Initiative against Diarrheal and Enteric Diseases in Africa and Asia (IDEA), together with representatives from the World Health Organization, the US National Institutes of Health, International Vaccine Institute, Agence de médecine préventive, NGOs (Save the Children) and UNICEF, met in Hanoi (Vietnam) to share progress in terms of prevention and control interventions on water, sanitation and hygiene (WASH), surveillance and oral cholera vaccine use.

This paper reports on the country situation, gaps identified in terms of cholera prevention and control and strategic interventions to bridge these gaps.
\end{abstract}

Keywords: Cholera, Asia, Water, Sanitation and hygiene (WASH), Cholera vaccine, IDEA

\section{Background}

Cholera represents an important public health problem in many settings. Annually, 2.8 million cases and 91,500 deaths occur in cholera endemic countries [1]. Beyond direct health concerns, cholera also presents a significant economic burden [2].

In addition to poor sanitation and inappropriate clean water supply, insufficient health literacy and community mobilization, absence of national plans and cross-border

\footnotetext{
* Correspondence: valentina.picot@fondation-merieux.org

The list of authors is in alphabetical order except for the last five with equal contribution.

${ }^{\dagger}$ Hubert Endtz, N. K. Ganguly, Dominique Legros, Valentina Picot and G. Balakrish Nair contributed equally to this work.

${ }^{5}$ Fondation Mérieux, 17 rue Bourgelat, 69002 Lyon, France

Full list of author information is available at the end of the article
}

collaborations are major factors impeding optimal control of cholera in endemic countries. Poor knowledge of the real burden of cholera due to substantial underreporting is also another obstacle [3-5]. Potential factors which will worsen the situation in the coming years are climate change, urbanization, increase in population density and, (further) rise of social inequalities [6].

Progress towards better hygiene and sanitation will be faster if a multidisciplinary and multi-sectoral approach is developed and implemented. Implementation of such strategy requires action under two key pillars: 1) increase political and financial support for cholera control and;2) strengthen multi-sectoral cholera prevention and control programs.

(c) The Author(s). 2018 Open Access This article is distributed under the terms of the Creative Commons Attribution 4.0 International License (http://creativecommons.org/licenses/by/4.0/), which permits unrestricted use, distribution, and reproduction in any medium, provided you give appropriate credit to the original author(s) and the source, provide a link to the Creative Commons license, and indicate if changes were made. The Creative Commons Public Domain Dedication waiver (http://creativecommons.org/publicdomain/zero/1.0/) applies to the data made available in this article, unless otherwise stated. 


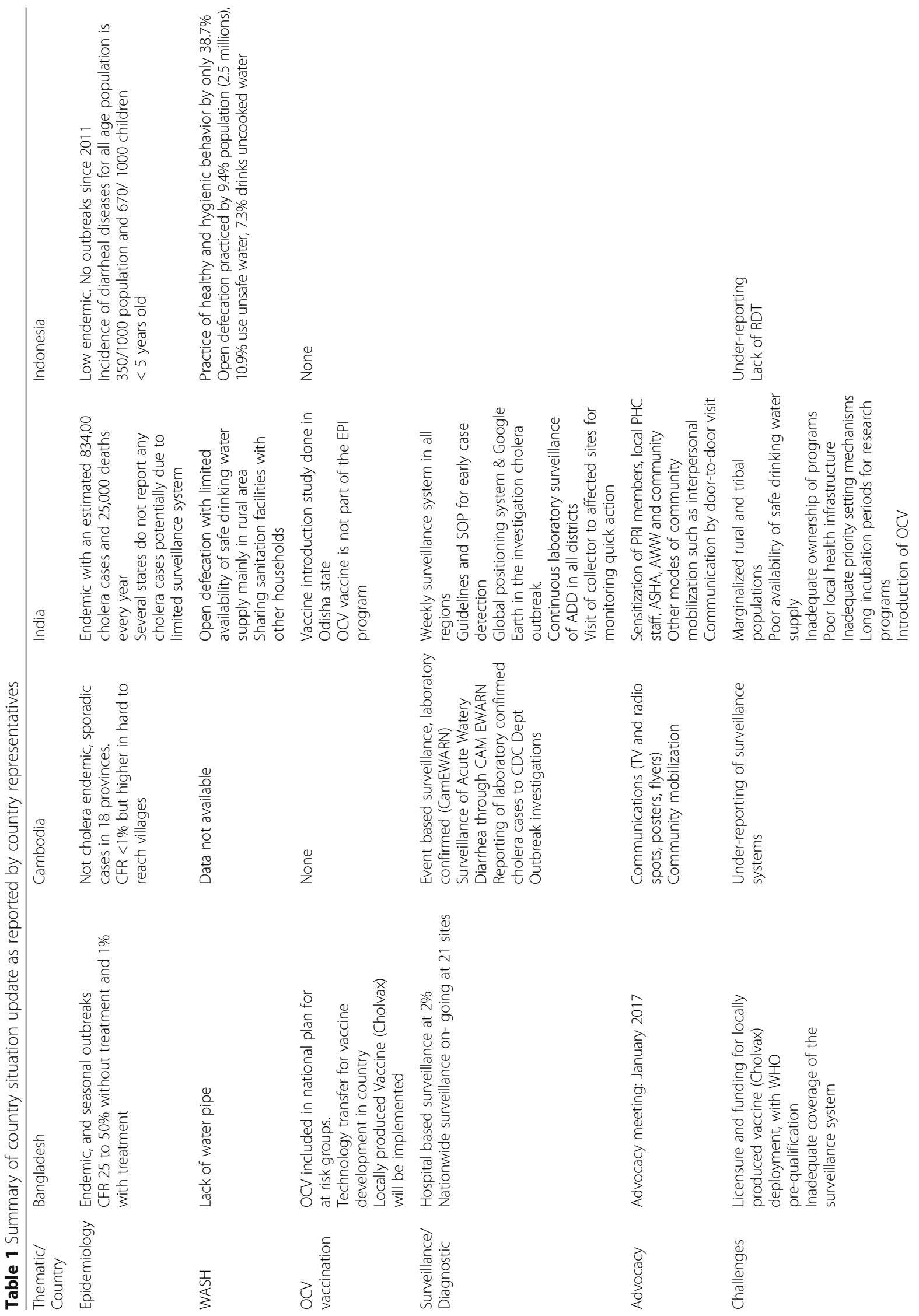




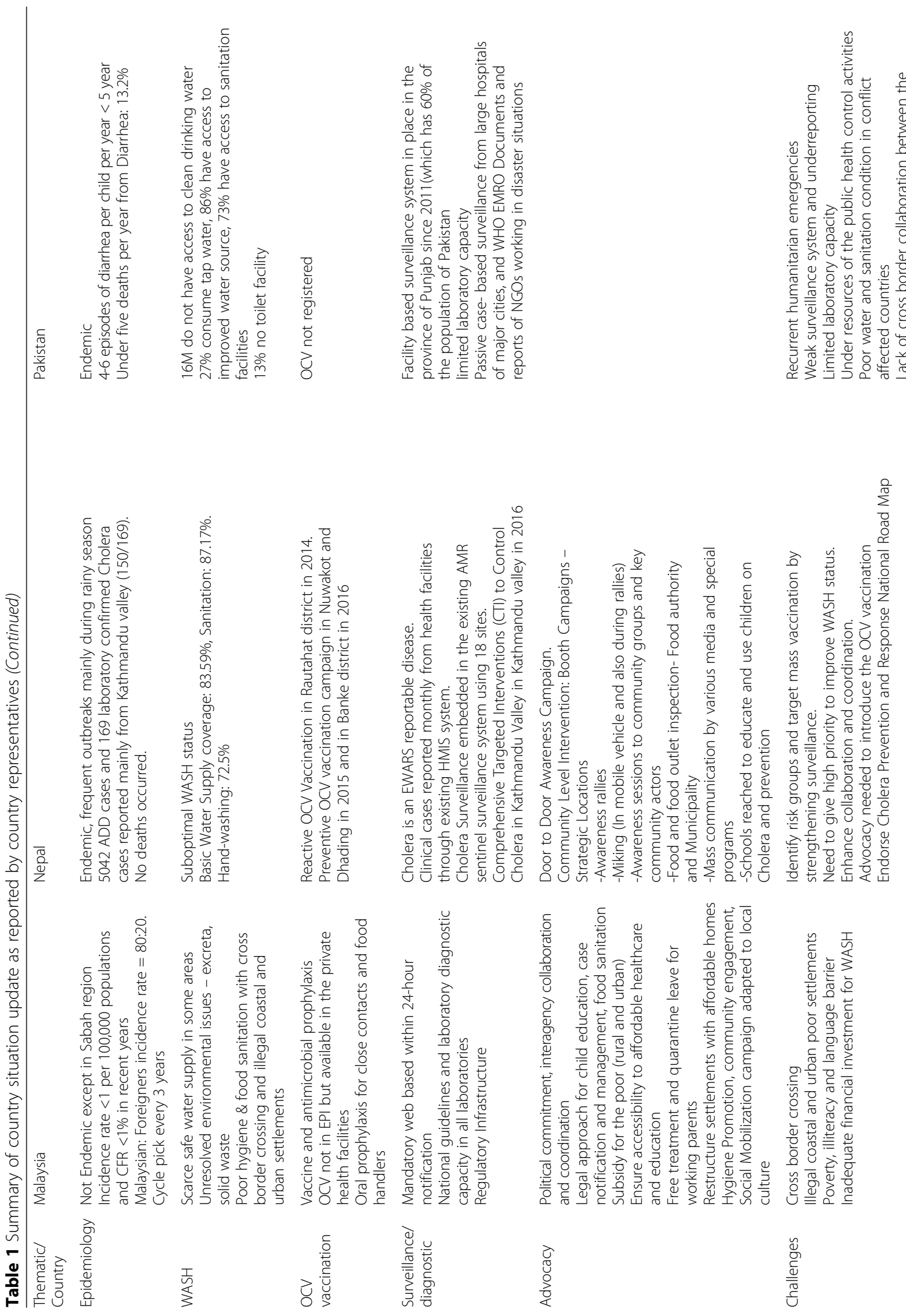




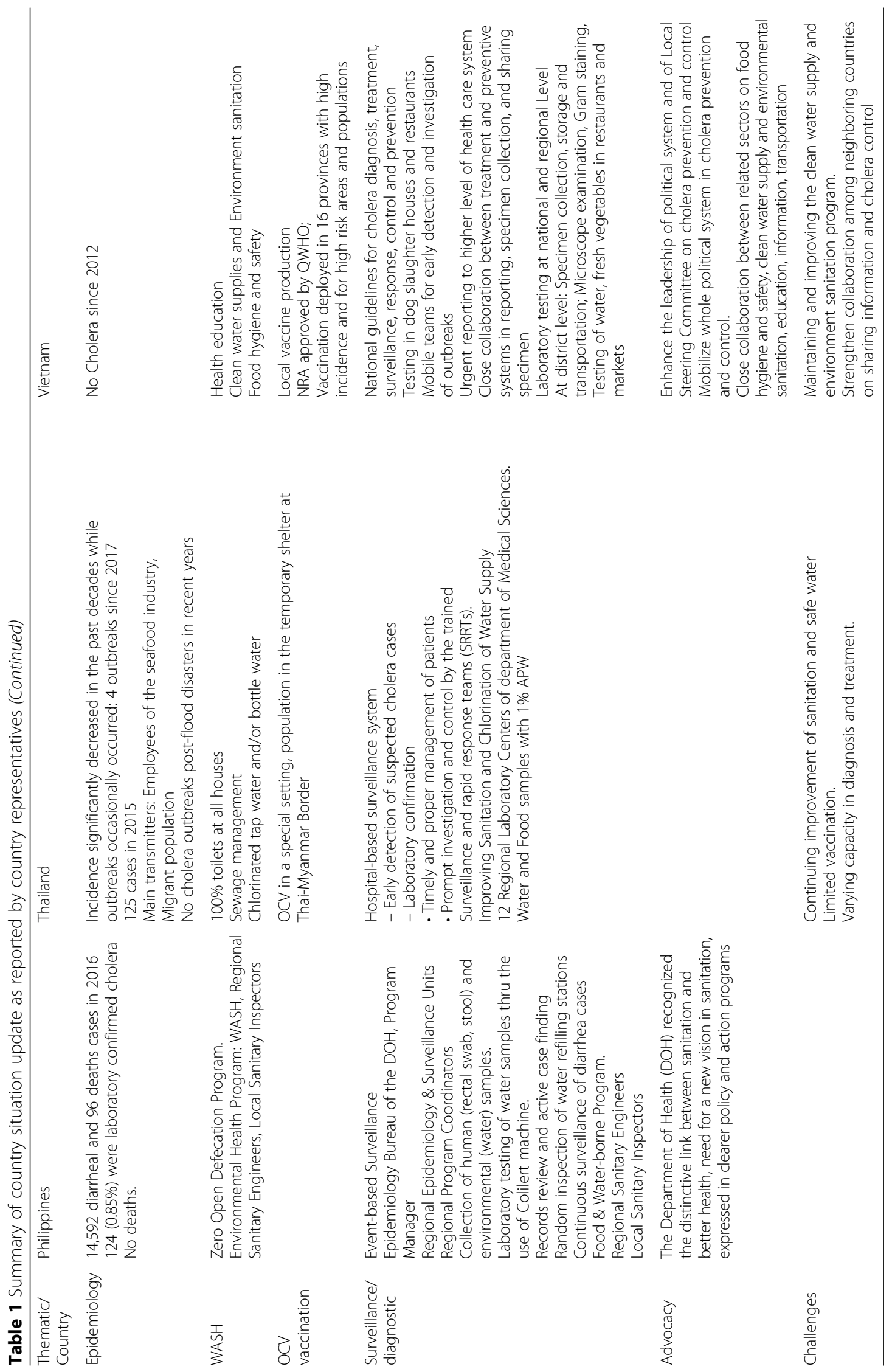


Table 2 The use of oral cholera vaccine stockpile in 2013-2016

\begin{tabular}{llll}
\hline Year & Type of Campaign & Number & Country \\
\hline 2013 & Endemic & 2 & Haiti (2) \\
2014 & Endemic & 10 & DRC, Guinea, Haiti (8) \\
& Humanitarian crisis & 7 & South Sudan, Ethiopia \\
2015 & Outbreak & 4 & Malawi, South Soudan, Iraq, Nepal \\
& Humanitarian crisis & 6 & South Sudan (3), Tanzania, \\
2016 & Endemic & 1 & Cameroon, Malawi \\
& Humanitarian crisis & 3 & Niger, South Sudan (2) \\
& Outbreak & 2 & Malawi, Zambia
\end{tabular}

In accordance with these pillars, the Initiative against Diarrheal and Enteric Diseases in Africa and Asia (IDEA) was born in 2011. IDEA is an independent and multidisciplinary network of professionals from cholera-prone countries in Asia and Africa, in collaboration with national and international stakeholders. IDEA's main goal is to facilitate and support the implementation of relevant prevention and control interventions on water, sanitation and hygiene (WASH), and on the use of oral cholera vaccine $(\mathrm{OCV})$ by sharing information and best practices and to raise awareness on the country specific cholera situation. Between 2015 and 2016, four IDEA workshops have been successfully achieved in Asia and Africa. The fifth IDEA meeting took place in Vietnam (Hanoi, 6-9 March 2017) and involved experts from 10 Asian cholera-prone countries (Bangladesh, Cambodia, India, Indonesia, Malaysia, Nepal, Philippines, Pakistan, Thailand, and Vietnam) together with representatives from the WHO, the US National Institutes of Health, International Vaccine Institute, Agence de médecine préventive, NGOs (Save the Children, $\mathrm{StC}$ ), and UNICEF.

Country representatives shared their respective country situation, and progress in terms of WASH, surveillance and OCV use. Representatives from different health agencies provided an overview of available initiatives, interventions and tools in Asia. Following the plenary sessions, participants worked in subgroups to identify gaps in terms of cholera prevention and control and to discuss strategic interventions to bridge these gaps.

\section{Country situation}

Update on cholera epidemiology, progress in the prevention and control of cholera and a mapping of country capacities were presented (Table 1). Suboptimal WASH including lack of safe water supply, appropriate sanitation facilities and persistence of open defecation were among factors that contribute to persistent cholera outbreaks. OCV has been used in Bangladesh, India, and Nepal but is not included in the National Immunization Programs. Cholera surveillance systems are in place in all participating countries but the type of surveillance and the extent of coverage differ considerably between countries. Awareness campaigns and community mobilization are regularly conducted in order to sensitize the public to simple preventive measures. Each country faces several challenges but improving WASH and increasing the coverage areas of surveillance systems were commonly reported.

\section{Existing interventions on cholera prevention and control in Asia}

UNICEF chairs the WASH working group of the Global Task Force on Cholera Control (GTFCC). The WASHGTFCC working group has developed technical briefs and set-up a study to estimate the effectiveness of households' disinfection practices.

WASH is also one of the main actions of StC, an international non-governmental organization that promotes children's rights. The StC global approach to cholera includes emergency health units, prepositioning stocks in eight countries, and a multi-sectoral approach. The objectives are to i) keep fecal matter away from drinking water, ii) inactivate cholera in contaminated water and iii) provide WASH facilities for medical teams and patients.

Another significant preventive tool available now is the global stockpile of OCV that was created in 2013 as an additional tool to help control cholera epidemics [7]. The WHO, UNICEF, and the Delivering Oral Vaccine Effectively (DOVE) project work in close collaboration

Table 3 List of oral cholera vaccine technology transfer by the International Vaccine Institute

\begin{tabular}{|c|c|c|c|}
\hline Company (Country) & Vaccine & Partnership & Stage of development \\
\hline Vabiotech (Vietnam) & mORCVAX & $\begin{array}{l}\text { IVI re-formulated redeveloped the process to } \\
\text { meet WHO standards }\end{array}$ & Licensed in Vietnam \\
\hline \multirow[t]{2}{*}{ Shanat (India) } & \multirow[t]{2}{*}{ Shancol } & \multirow[t]{2}{*}{ Technology transfer May 2008} & Licensed in India (Feb 2009) \\
\hline & & & WHO prequalified Sep 2011 \\
\hline \multirow[t]{2}{*}{ Eubiologics (Korea) } & \multirow[t]{2}{*}{ Euvichol } & \multirow[t]{2}{*}{ Technology transfer May 2010-2011 } & Korean export license 2014 \\
\hline & & & WHO prequalified Dec 2015 \\
\hline Incepta (Bangladesh) & Cholvax & Technology transfer May 2014 & $\begin{array}{l}\text { IVI conducting clinical trial in Bangladesh, } \\
\text { license expected in 2017-2018 }\end{array}$ \\
\hline
\end{tabular}


to ensure that at-risk populations will benefit from $\mathrm{OCV}$ in an appropriate and effective manner.

The dynamic creation by the establishment of stockpile has played a key role in increased use of OCV [8-11] (Table 2). However, vaccine availability remains a major barrier limiting mass vaccination interventions. Two campaigns were conducted in South Sudan (2015) and in Zambia (2016) to evaluate the efficacy of a single dose strategy during outbreaks. The results showed that vaccinating twice the number of people with a single dose can prevent more cases and deaths during an outbreak by providing rapid herd protection. Similar findings have been provided by a modeling study that assessed the impact of one-dose OCV versus 2-doses in outbreak settings [12].

Other novel strategies including self-administration of the second dose (fisherman living in floating homes), out of cold chain use during distribution (Guinea 2012) and OCV delivery combined with other interventions (Refugee camps, Cameroon 2015) have also been tested and provide evidence of the feasibility of conducting OCV campaigns in a variety of scenarios.

To help developing country vaccine manufacturers, the International Vaccine Institute (IVI) engaged in a technology transfer development strategy (Table 3). Long-term efficacy of Shanchol [13] and safety and immunogenicity of Euvichol [14] have already been assessed. Cholvax is currently under evaluation in a non-inferiority trial to Shanchol in Bangladesh. In parallel, an individually randomized placebo-controlled trial to evaluate the use of a single dose in an endemic setting was completed [15].

\section{Workshop session}

To elicit more consideration for the prevention and control of cholera in participating countries, a brainstorming breakout session was held. The first part of the session was focused on what should countries aim at in terms of cholera prevention and control. There were two clusters of countries in terms of mid-term objectives depending on where they currently stand in cholera prevention and control (Fig. 1). Cambodia, Malaysia, Thailand and Vietnam aim at eliminating cholera in the coming years while recognizing cholera as a public health problem was the main mid-term objective for others.

Participants identified five main areas of strategic intervention to bridge the gaps and hence to reach the objectives of countries in terms of cholera prevention and control.

\section{Implementation/reinforcement of surveillance systems}

(Fig. 2)

Currently, surveillance systems are patchy or minimal. Countries must strengthen the existing surveillance systems both in terms of coverage and capacity (e.g. laboratory diagnostic tests). This would allow early case detection and immediate response. Regular analysis and dissemination of data at the national and neighborhood level is also believed to act as a driver in the prevention and control of cholera.

Water, sanitation and hygiene promotion (Fig. 3)

WASH is universally recognized as a major component of preventing several infectious diseases [16]. Implementation of successful proactive WASH campaigns requires political will and community engagement. Tailored messages should be developed to increase awareness of open defection, food and environmental safety and hygienic practices. Special attention should be given to schools. Engagement of political leaders could help in funding WASH priorities and in implementing food and water safety laws.

Deployment of oral cholera vaccine (Fig. 4)

$\mathrm{OCV}$ is considered as a supplementary tool for cholera prevention and control [17]. Pre-emptive and reactive $\mathrm{OCV}$ vaccination programs in cholera hot spots in several African and Asian countries have shown promising results [9-11] and should be sustained. Cost-effectiveness

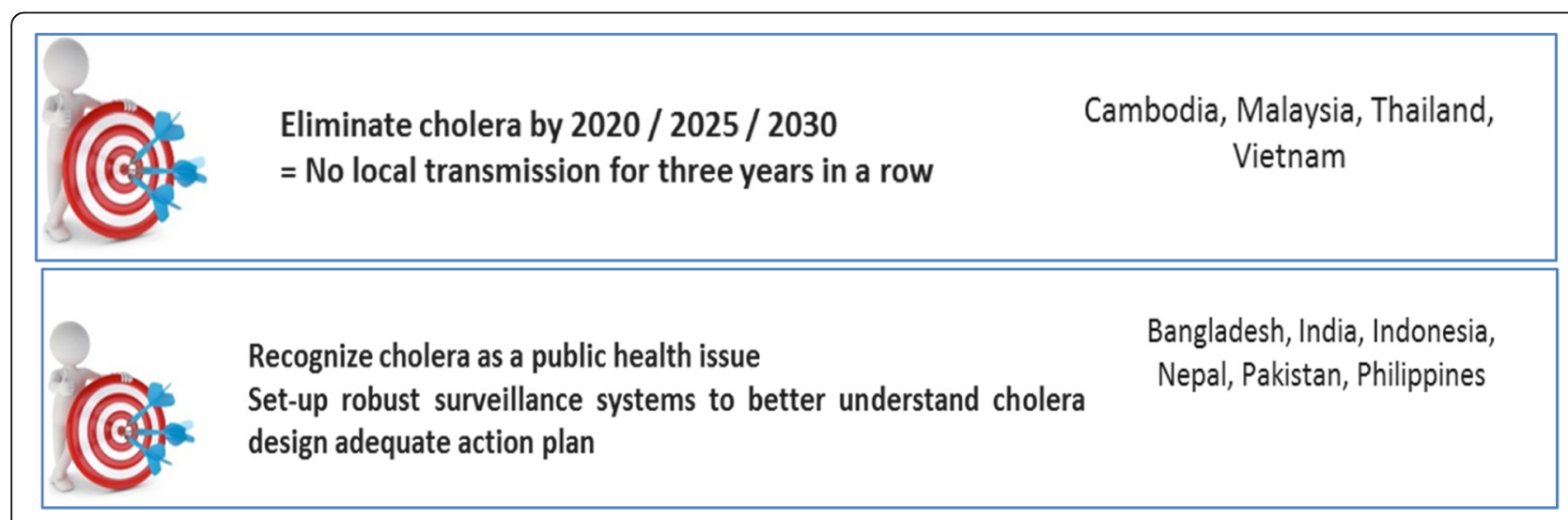

Fig. 1 Countries' aims for cholera prevention and control 


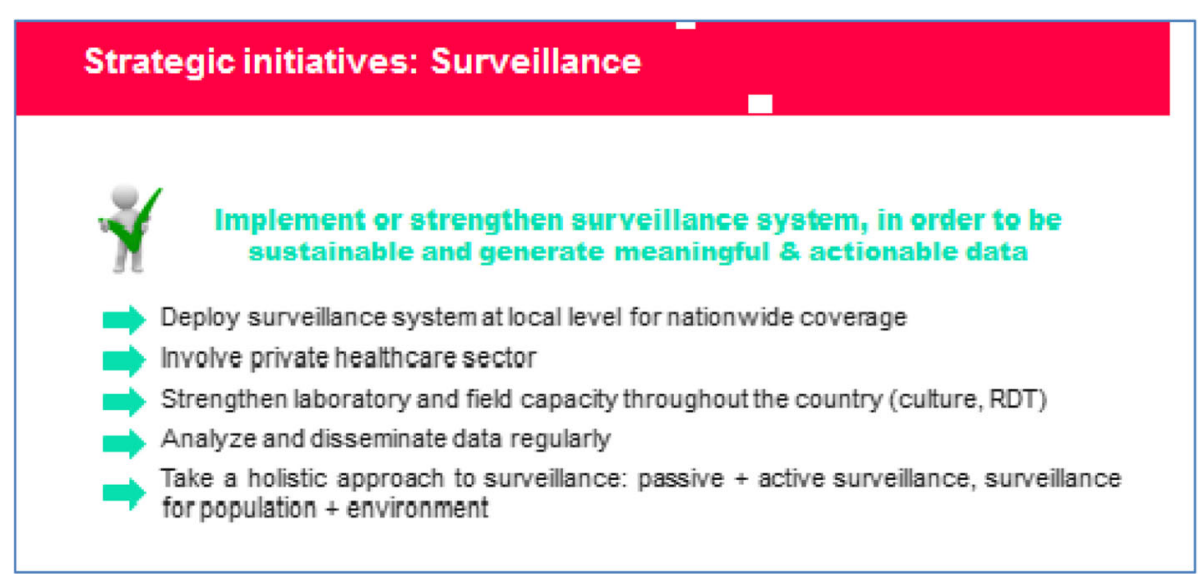

Fig. 2 Implementation/reinforcement of surveillance systems

analysis of mass cholera vaccination campaigns is a key consideration for optimizing OCV deployment.

\section{Social mobilization and health promotion (Fig. 5)}

To be effective, community mobilization should be based on outreach and awareness campaigns that improve knowledge on the disease, prevention and existing treatment. They should provide transparent sharing of information and proper education about routes of transmission and prevention measures. Appropriate involvement of media and schools could ensure fast spread of the information.

\section{Collaboration (Fig. 6)}

Cholera preparedness and responses should include inter-sectoral partnership between health authorities at national and international level, civil society and other stakeholders. Cholera epidemics commonly occur in a cross-border manner, emphasizing the importance of cross-border cooperation to control and prevent the spread of the disease.

\section{Conclusions}

Cholera remains a continuous threat with high health and economic burden in several South Asian countries. Despite tremendous efforts, prevention and control of cholera suffers from a number of challenges and issues in Asia. Inadequate WASH was identified as a major barrier in the prevention and control of cholera. Countries believe that WASH responses were often reactive and the criteria to trigger WASH responses were often unclear. Funding of WASH priorities remains also a challenge. This might be due to the difficulties related to measuring quantitatively the effectiveness and sustainability of WASH, as compared to vaccination which is precisely measured and evaluated using immunological or surveillance data, or directly by determining vaccination status. The group recommended that priority WASH interventions in emergency situation should include: i) increased water supply, ii) improved quality of water supplied, iii) increased access to excreta disposal facilities, solid waste collection and disposal, hand washing facilities, soap and water storage vessels and iv) hygiene education and social mobilization.

\section{Strategic initiatives: WASH}

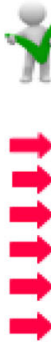

Implement / Speed up WASH implementation

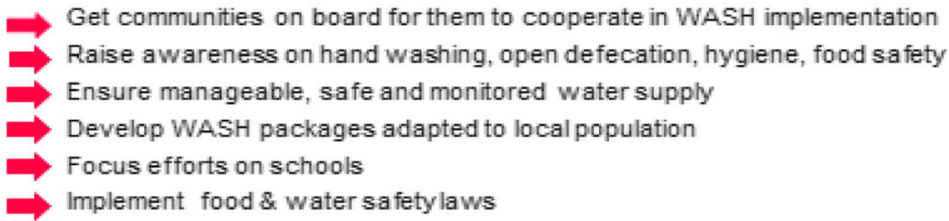

Fig. 3 Water, Sanitation and Hygiene promotion 


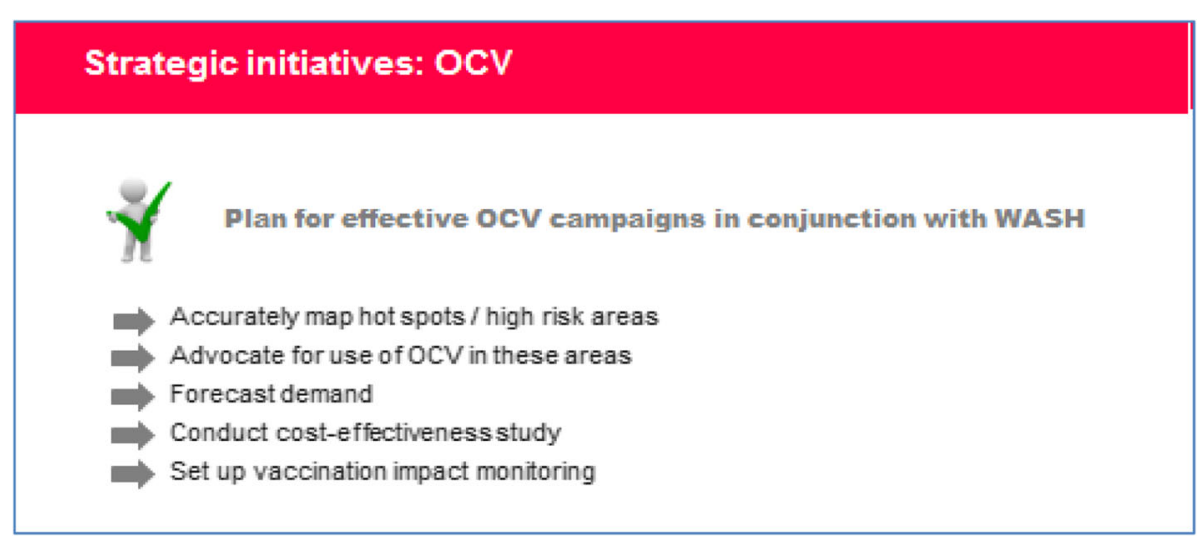

Fig. 4 Deployment of oral cholera vaccine

Weak surveillance systems, underreporting and limited laboratory capacities have been reported by country representatives who advocated for reinforcement of active and passive cholera surveillance system: capacity building, training, guidelines, and equipment facilities. Participating countries recommended that the Cholera Prevention and Response National Road Map should also be endorsed urgently.

OCV have the added advantage of herd protection which further decrease significantly the number of cases. Thanks to technology transfer, the OCV stockpile will grow with more vaccines being manufactured by different companies. Vaccine price could also be positively impacted by multiplying manufacturers. The group concluded that OCV should be introduced and used in different ways according to the country situation (special populations, integrated in the existing immunization programs or used in emergency situations). The use of one-dose OCV regimen could also be a promising solution during emergency situations. Other innovative OCV delivery strategies are also being tested. This includes: $\checkmark$ A self-administered second dose for the fishermen in "floating homes" living on Lake Chilwa is carried out by MSF. The second dose is given together with first dose that will be home-based self-administration,

A community-led self-administrated second dose on the six islands of Lake Chilwa carried out by AMP. The second dose is given to community leaders and kept in large cool boxes to be administrated under direct observation of the leader.

Evidence supports that killed whole cell vaccines are stable at high temperature for long periods $[9,18,19]$. Therefore, vaccine can be kept under cold chain in central stock but used out of the cold chain during distribution in hard-to-reach areas.

Provision of necessary supply will have the greatest impact on cholera burden if it is coupled with educational programs, community engagement and mobilization. The efficacy of a number of actions (e.g. door-to-door visits, placards, slogans, banners, special annual campaign) has already been tested and ought to be sustained. Outbreaks should be investigated and controlled as rapidly as

\section{Strategic initiatives: Social mobilization \& health promotion}

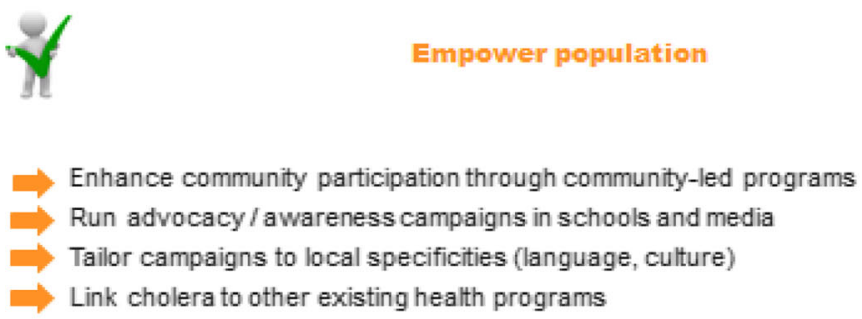

Fig. 5 Social mobilization and health promotion 


\section{Strategic initiatives: Collaborations}

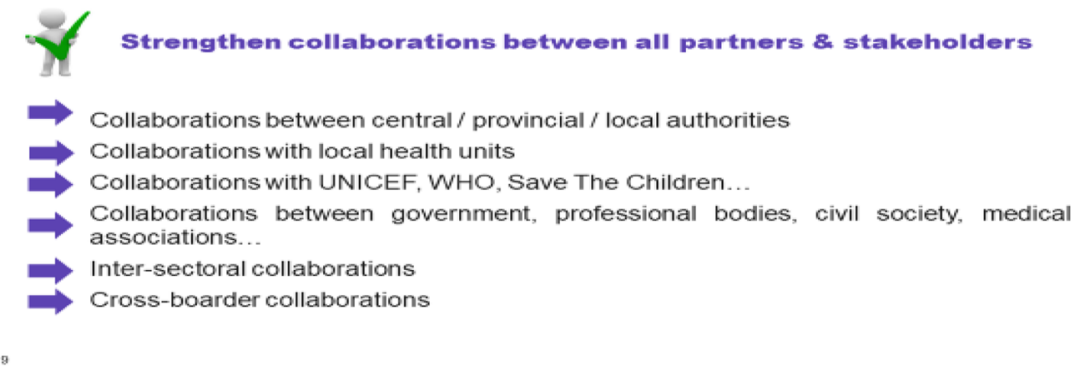

Fig. 6 Collaboration

possible by means of communication. Low-cost nudges behavior changes with a preventive approach can could help to increase compliance to hand-washing. In a nudgebased intervention study (i.e. positive reinforcement to influence people's behavior) carried in rural Bangladesh, hand-washing with soap increased from $4 \%$ at baseline to $68 \%$ the day after nudges were completed and $74 \%$ at 2 and 6 weeks post intervention [20].

Cholera still causes stigma as it is said to be a 'forgotten disease' mainly affecting 'poor people'. Outreach meetings including public and private stakeholders and the general population are warranted to recognize that cholera is not only a health problem but also the direct consequence of poor WASH, linked to various environmental, climatic and socio-economic situations. Cholera can be prevented and controlled via complementary, synergistic and multidisciplinary interventions including access to safe water supply, end of open defection, increased hygiene, political engagement, community mobilization, prompt case management and vaccination.

\section{Perspective}

Integrated multi-sectoral approaches have proven to be the best mechanism to implement effective strategies for the prevention and control of infectious diseases. Coordinated stakeholder activities are key components of disease control success. In this perspective Fondation Mérieux hosting organization along with present stakeholder during the meeting announces its full commitment to the coordinated strategy and join its cholera activities along with other partners within the Global Task Force on Cholera Control to implement the renewed strategy for cholera control while building on existing achievements.

\section{Abbreviations}

GTFCC: Global Task Force on Cholera Control; IDEA: Initiative against Diarrheal and Enteric Diseases in Africa and Asia; OCV: Oral cholera vaccine; StC: Save the Children; WASH: Water, sanitation and hygiene

\section{Acknowledgments}

The authors express their gratitude to the National Institute for Hygiene and Epidemiology (Vietnam) for hosting the meeting.

\section{Funding}

The conference was funded by Fondation Mérieux and unrestricted grants from Sanofi Pasteur, bioMérieux, and Valneva.

The publication cost of this article was founded by the Mérieux Foundation (Lyon-France).

\section{Authors' contributions}

$V P, H E, N K G, D L$, and GBN conceived and planned the conference. VP and CG coordinated the meeting. MSE, VP, NKG, DL and GBN wrote the first draft of the manuscript. All authors read, commented and approved the final draft for publication and agreed to be accountable for all aspects of the work. The article is original and has not been published elsewhere.

Consent for publication

Non-applicable.

\section{Competing interests}

The authors declare that they have no competing interests.

\section{Publisher's Note}

Springer Nature remains neutral with regard to jurisdictional claims in published maps and institutional affiliations.

\section{Author details}

${ }^{1}$ Bangladesh Pediatric Association, Shahbag, Dhaka, Bangladesh. ${ }^{2}$ Ministry of Health, Manila, Philippines. ${ }^{3}$ Save the Children, London, UK. ${ }^{4}$ National Institute of Hygiene and Epidemiology, Hanoi, Vietnam. ${ }^{5}$ Fondation Mérieux, 17 rue Bourgelat, 69002 Lyon, France. ${ }^{6}$ UNICEF, Bangkok, Thailand. ${ }^{7}$ Ministry of Health, Kuala Lumpur, Malaysia. ${ }^{8}$ Ministry of Health Cambodia, Phnom Penh, Cambodia. ${ }^{9}$ Ministry of Health, Bangkok, Thailand. ${ }^{10}$ Indonesia Pediatric Society, Jakarta, Indonesia. ${ }^{11} \mathrm{~S}^{\prime} \mathrm{O}$ A University, Bhubaneswar, Odisha, India. ${ }^{12}$ Delivering Oral Vaccine Effectively, Manila, Philippines. ${ }^{13}$ International Vaccine Institute, Seoul, South Korea. ${ }^{14}$ Pakistan Pediatric Association, Karachi, Pakistan. ${ }^{15}$ Agence de Médecine Préventive, Madrid, Spain. ${ }^{16}$ Ministry of Health, Hanoi, Vietnam. ${ }^{17}$ Ministry of Health, Kathmandu, Nepal.

${ }^{18}$ International Centre for Diarrhoeal Disease Research (icddr,b), Dhaka, Bangladesh. ${ }^{19}$ Hopital Edouard Herriot, Hospices Civils de Lyon, Lyon, France. ${ }^{20}$ Translational Health Science and Technology Institute, Pali, Haryana, India.

${ }^{21}$ Mid city Hospital, Lahore, Pakistan. ${ }^{22}$ Program for Appropriate Technology in Health (PATH), New Delhi, India. ${ }^{23}$ Institut Pasteur, Hô-Chi-Minh, Vietnam. ${ }^{24}$ Group for Technical Assistance, Kathmandu, Nepal. ${ }^{25}$ World Health Organization, Geneva, Switzerland. ${ }^{26}$ World Health Organization, New Delhi, India. 
Published: 7 December 2018

\section{References}

1. Ali M, Nelson AR, Lopez AL, Sack DA. Updated global burden of cholera in endemic countries. PLoS Negl Trop Dis. 2015;9(6):e0003832. https://doi.org/ 10.1371/journal.pntd.0003832.

2. Oxford Economics. Economic impact of a cholera epidemic on Mozambique and Bangladesh. A report for the International Vaccine Institute, 2010

3. Ali M, Lopez AL, You YA, Kim YE, Sah B, Maskery B, et al. The global burden of cholera. Bull World Health Organ. 2012;90(3):209-218A. https://doi.org/10. 2471/BLT.11.093427.

4. Kanungo S, Sah BK, Lopez AL, Sung JS, Paisley AM, Sur D, et al. Cholera in India: an analysis of reports, 1997-2006. Bull World Health Organ. 2010;88(3): 185-91. https://doi.org/10.2471/BLT.09.073460.

5. Zuckerman JN, Rombo L, Fisch A. The true burden and risk of cholera: implications for prevention and control. Lancet Infect Dis. 2007;7(8):521-30.

6. Legros D. Cholera cases reported by year, 1989-2015. WHO 2017. http:// www.who.int/immunization/sage/meetings/2017/apri//Legros_OCV_ cholera_global_situation_SAGE_Apr2017.pdf. Accessed 5 Nov 2018.

7. Oral cholera vaccine stockpile. WHO. http://www.who.int/cholera/vaccines/ ocv_stockpile_2013/en/. Accessed 5 Nov 2018.

8. Luquero FJ, Grout L, Ciglenecki I, Sakoba K, Traore B, Heile M, et al. Use of Vibrio cholerae vaccine in an outbreak in Guinea. N Engl J Med. 2014; 370(22):2111-20. https://doi.org/10.1056/NEJMoa1312680.

9. Ciglenecki I, Sakoba K, Luquero FJ, Heile M, Itama C, Mengel M, et al. Feasibility of mass vaccination campaign with oral cholera vaccines in response to an outbreak in Guinea. PLoS Med. 2013;10(9):e1001512. https:// doi.org/10.1371/journal.pmed.1001512.

10. Luquero FJ, Grout L, Ciglenecki I, Sakoba K, Traore B, Heile M, et al. First outbreak response using an oral cholera vaccine in Africa: vaccine coverage, acceptability and surveillance of adverse events, Guinea, 2012. PLoS Negl Trop Dis. 2013;7(10):e2465. https://doi.org/10.1371/journal.

11. Khatib AM, Ali M, von Seidlein L, Kim DR, Hashim R, Reyburn R, et al. Effectiveness of an oral cholera vaccine in Zanzibar: findings from a mass vaccination campaign and observational cohort study. Lancet Infect Dis. 2012:12(11):837-44. https://doi.org/10.1016/S1473-3099(12)70196-2.

12. Azman AS, Luquero FJ, Ciglenecki I, Grais RF, Sack DA, Lessler J. The impact of a one-dose versus two-dose Oral cholera vaccine regimen in outbreak settings: a modeling study. PLoS Med. 2015;12(8):e1001867. https://doi.org/ 10.1371/journal.pmed.1001867.

13. Bhattacharya SK, Sur D, Ali M, Kanungo S, You YA, Manna B, et al. 5-year efficacy of a bivalent killed whole-cell oral cholera vaccine in Kolkata, India: a cluster-randomised, double-blind, placebo-controlled trial. Lancet Infect Dis. 2013;13(12):1050-6. https://doi.org/10.1016/S1473-3099(13)70273-1.

14. Baik YO, Choi SK, Olveda RM, Espos RA, Ligsay AD, Montellano MB, et al. A randomized, non-inferiority trial comparing two bivalents killed, whole cell, oral cholera vaccines (Euvichol vs Shanchol) in the Philippines. Vaccine. 2015;33(46):6360-5. https://doi.org/10.1016/j.vaccine.2015.08.075.

15. Qadri F, Wierzba TF, Ali M, Chowdhury F, Khan Al, Saha A, et al. Efficacy of a single-dose, inactivated Oral cholera vaccine in Bangladesh. N Engl J Med. 2016;374(18):1723-32. https://doi.org/10.1056/NEJMoa1510330.

16. Taylor DL, Kahawita TM, Cairncross S, Ensink HJ. The Impact of Water, Sanitation and Hygiene Interventions to Control Cholera: A Systematic Review. PLoS One. 2015;10(8):e0135676. https://doi.org/10.1371/journal. pone. 0135676

17. World Health Assembly. Cholera: mechanism for control and prevention. 24 May 2011. http://apps.who.int/gb/ebwha/pdf_files/WHA64/A64_R15-en.pdf. Accessed 15 Aug 2017

18. Ahmed ZU, Hoque MM, Rahman AS, Sack RB. Thermal stability of an oral killed-cholera-whole-cell vaccine containing recombinant B-subunit of cholera toxin. Microbiol Immunol. 1994;38(11):837-42.

19. Saha A, Khan A, Salma U, Jahan N, Bhuiyan TR, Chowdhury F, et al. The oral cholera vaccine Shanchol ${ }^{T M}$ when stored at elevated temperatures maintains the safety and immunogenicity profile in Bangladeshi participants. Vaccine. 2016;34(13):1551-8. https://doi.org/10.1016/j.vaccine.2016.02.020.

20. Dreibelbis R, Kroeger A, Hossain K, Venkatesh M, Ram PK. Behavior Change without Behavior Change Communication: Nudging Handwashing among Primary School Students in Bangladesh. Int J Environ Res Public Health. 2016;13(1). https://doi.org/10.3390/ijerph1301012.

\section{Ready to submit your research? Choose BMC and benefit from:}

- fast, convenient online submission

- thorough peer review by experienced researchers in your field

- rapid publication on acceptance

- support for research data, including large and complex data types

- gold Open Access which fosters wider collaboration and increased citations

- maximum visibility for your research: over $100 \mathrm{M}$ website views per year

At $\mathrm{BMC}$, research is always in progress.

Learn more biomedcentral.com/submissions 